\title{
Ionic Liquid Control Crystal Growth to Enhance Planar Perovskite Solar Cells Efficiency
}

\author{
Ji-Youn Seo, Taisuke Matsui, Jingshan Luo, Juan-Pablo Correa-Baena, Fabrizio Giordano, \\ Michael Saliba, Kurt Schenk, Amita Ummadisingu, Konrad Domanski, \\ Mahboubeh Hadadian, Anders Hagfeldt, Shaik M. Zakeeruddin, Ullrich Steiner, \\ Michael Grätzel, and Antonio Abate*
}

\begin{abstract}
Perovskite solar cells (PSCs) have had a lasting impression on the scientific community because of their fast progress as high efficient and low cost technology. Starting from the seminal work of Kojima et al. in 2009, in only seven years power conversion efficiencies above $22 \%$ have already been reported and certified. ${ }^{[1-4]}$ In aspect of economic and technological analysis, one promising route to industrialization of PSCs is to take advantage of the complementary band gaps of perovskite and silicon solar cells, i.e., to create a perovskite-silicon tandem. In a tandem architecture the perovskite can be deposited on the top of bottom cell to potentially overtake the Shockley Queisser limitation for a single junction device. ${ }^{[5]}$ This strategy is promising, but it requires low-temperature processing $\left(100{ }^{\circ} \mathrm{C}\right)$ to avoid damaging of the bottom silicon cell. Currently, the highest efficient PSCs employ a mesoscopic $\mathrm{TiO}_{2}$ electron contact, which is processed at temperature above
\end{abstract}

J.-Y. Seo, Dr. J. Luo, Dr. F. Giordano, Dr. M. Saliba, A. Ummadisingu, K. Domanski, Dr. S. M. Zakeeruddin, Prof. M. Grätzel, Dr. A. Abate

Swiss Federal Institute of Technology (EPFL)

Laboratory of Photonics and Interfaces

Station 6, CH-1015 Lausanne, Switzerland

E-mail: antonio.abate@epfl.ch,

antonioabate83@gmail.com

T. Matsui

Advanced Research Division

Materials Research Laboratory

Panasonic Corporation

1006 Kadoma, Kadoma City, Osaka 571-8501, Japan

Dr. J.-P. Correa-Baena, M. Hadadian, Prof. A. Hagfeldt

Laboratory of Photomolecular Science

Institute of Chemical Sciences and Engineering

École Polytechnique Fédérale de Lausanne

$\mathrm{CH}-1015$ Lausanne, Switzerland

Dr. K. Schenk

Institut des Sciences et Ingénierie Chimiques

Institut de Physique des Systèmes Biologiques

École Polytechnique Fédérale de Lausanne

$\mathrm{CH}-1015$ Lausanne, Switzerland

M. Hadadian

Department of Chemistry

Ferdowsi University of Mashhad

Mashhad 91779, Iran

Prof. U. Steiner, Dr. A. Abate

Adolphe Merkle Institute

University of Fribourg

Chemin des Verdiers 4, CH-1700 Fribourg, Switzerland

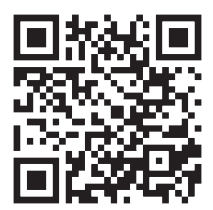

DOI: 10.1002/aenm.201600767
$400{ }^{\circ} \mathrm{C}$ and thus not compatible with the preparation of tandem devices. Although there are strategies to prepare mesoscopic $\mathrm{TiO}_{2}$ at low temperature, the easiest approach would be to use a planar perovskite device without mesoporous layer. ${ }^{[6]}$ We recently demonstrated low temperature processed $\mathrm{SnO}_{2}$ as electron contact in planar PSCs for tandem siliconperovskite solar cell. ${ }^{[7]}$ Although the efficiency of our tandem device was one of the highest reported, the top planar PSC was poorly performing compared to a mesoscopic $\mathrm{TiO}_{2}$-based device. Therefore, to profit from using perovskite in tandem with other photovoltaic materials, planar devices need to be improved.

In planar PSCs, the crystallinity, morphology, thickness, and surface coverage of perovskite film are critical for the device performance. ${ }^{[8]}$ Several methods have been proposed to prepare high-quality perovskite layer, such as spin-coating, two-step sequential deposition, and vacuum vapor deposition. ${ }^{[3,9-12]}$ Even though the one-step spin-coating method enabled among the highest efficiencies, the perovskite films frequently showed poor surface coverage, which resulted in a reduced cell performance. ${ }^{[13]}$ To overcome these issues, control of perovskite crystal growth and morphology has been widely investigated using several additives in the perovskite precursor solution. ${ }^{[14-16]}$ Shahiduzzaman et al. made use of the low vapor pressure ionic liquid (IL) 1-hexyl-3-methylimidazolium chloride to control the film morphology by forming a uniform distribution of perovskite nanoparticles. ${ }^{[16]}$ Moore et al. demonstrated that methylammonium formate can be used as an additive to produce higher quality, crystalline perovskite films. ${ }^{[15]}$ Although these studies suggested that adding ILs in the perovskite precursor solution may help to prepare better solar cells, there are currently no reports that implemented this strategy to improve state-of-the-art planar PSCs.

In this work, we demonstrate that ionic liquids enable the highest ever reported stabilized power conversion efficiency for a planar perovskite solar cell. We show that compact perovskite films with larger crystalline domain can be prepared from solution by adding particular ionic liquids, such as methylammonium formate, to the precursors. We demonstrate that larger crystalline domains result is a more effective charge collection and thus better photovoltaic performances. We propose an ILdriven mechanism of crystallization as a new strategy to prepare high-efficiency planar perovskite solar cell.

ILs are well known for their extremely low vapor pressure, which makes them nonvolatile liquids. If added in small 
a)<smiles>C[NH3+]</smiles>

$\mathbf{I}^{-}$

Iodide<smiles>O=CO</smiles>

Formate

\section{Methylammonium}

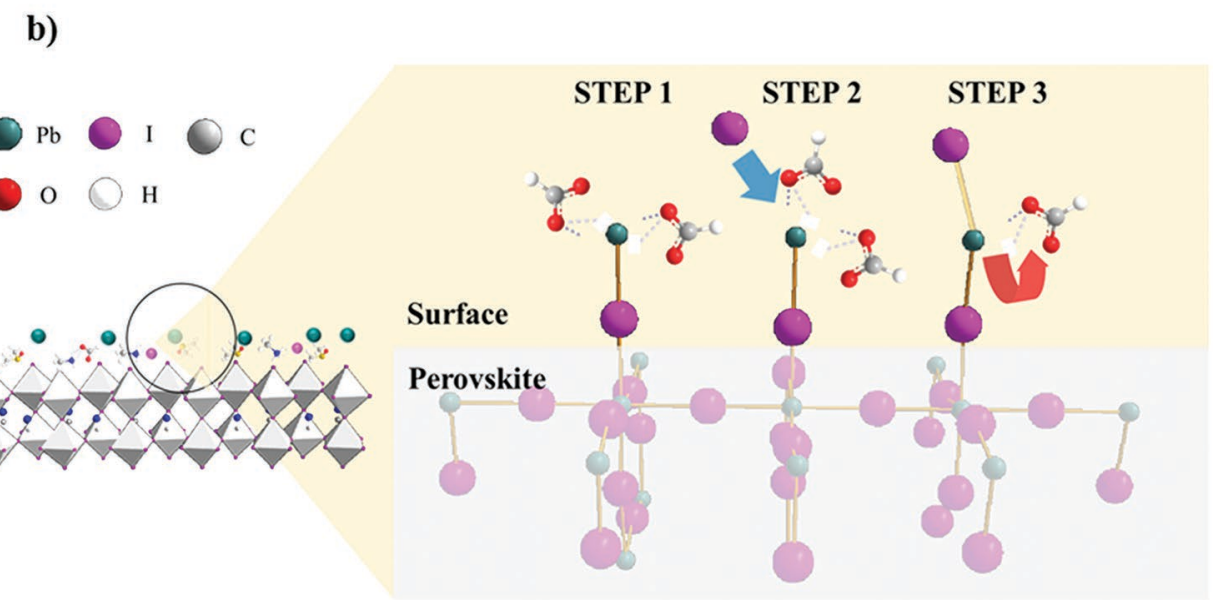

Figure 1. a) Molecular structure of the organic precursors methylammonium iodide and formate. b) Schematic of the proposed perovskite crystal growth mechanism as controlled by the formate anions.

amount (few mol\%) in the precursor solution, they remain in the perovskite film after all the solvent has evaporated during the annealing. ${ }^{[15,16]}$ For this study we focused on the IL methylammonium formate (MAF), owing to its affinity with the perovskite precursor methylammonium iodide (MAI), which is selected after screening morphology changes of perovskite films with other affinities including methlyammonium chloride (see the Supporting Information). ${ }^{[17]}$ The chemical structures of MAF and MAI are shown in Figure 1a. They have the same cation (methylammonium) and a different counter anion, formate (HCOO-) or iodide (I-). Since HCOO- is known to form metal-organic complex with $\mathrm{Pb2+}$, our working hypothesis was that the HCOO- influences the crystal growth of the perovskite interacting with $\mathrm{Pb} 2+.^{[18]}$ In Figure $1 \mathrm{~b}$, we depict a schematic view of the proposed mechanism: STEP (1) $\mathrm{HCOO}^{-}$coordinates with $\mathrm{Pb}^{2+}$ in solution and during the early stage of the crystal growth; STEP (2) the complex $\mathrm{HCOO}^{-}-\mathrm{Pb}^{+}$is gradually displaced by $\mathrm{Pb}^{+}-\mathrm{I}^{-}$when films are heated to $100{ }^{\circ} \mathrm{C}$; STEP (3) $\mathrm{HCOO}^{-}-\mathrm{Pb}^{+}$coordination is completely replaced by $\mathrm{Pb}^{+}-\mathrm{I}^{-}$enabling the crystal growth. Once the crystallization is completed MAF sits at the surface of the perovskite crystals as schematically presented in the left hand side of Figure $1 \mathrm{~b}$.

To investigate the impact of the MAF on the crystal growth, we prepared perovskite precursor solutions with and without $5 \mathrm{~mol} \%$ of MAF. Perovskite films were prepared on $\mathrm{SnO}_{2}$ deposited fluorine-doped tin oxide (FTO) substrates by spin coating the precursor solution in a nitrogen filled glovebox using the one-step antisolvent method. ${ }^{[19]}$ In Figure 2a we report the pictures of the perovskite films collected every $5 \mathrm{~s}$ after placing the substrates on a hotplate at $100^{\circ} \mathrm{C}$. It is evident that the film without MAF turns black earlier than the film with MAF. This simple experiment suggested that the crystal growth is slowed down by the presence of MAF. To look at the impact of the slower crystal growth on the film morphology, we collected scanning electron microscopy (SEM) images of the film surface after the annealing was completed $\left(1 \mathrm{~h}\right.$ at $\left.100^{\circ} \mathrm{C}\right)$. SEM images of perovskite films show that the average grain sizes are 170 and $325 \mathrm{~nm}$ without and with MAF, respectively. Therefore, a slower crystal growth induced larger average grain size. More interesting, we notice that the MAF inhibits the formation of grains smaller than $150 \mathrm{~nm}$, which represent a great portion of the size distribution in the film without the MAF (see statistical distribution in Figure 2b).

In order to investigate the impact of the MAF on the crystal structure of the perovskite, X-ray diffraction (XRD) patterns were collected from perovskite films with and without MAF on $\mathrm{SnO}_{2}$ substrates. The XRD spectra in Figure 3a show that the MAF-mediated perovskite is rather similar to the non-MAF film. This indicates that the HCOO- does not induce polymorphism or variation of the crystal lattice, even if it has a large influence on the perovskite film morphology, as shown in Figure 2. Furthermore, the fact that the diffraction pattern is the same, despite the size of HCOO- being larger than I- (HCOO$249 \AA$ > I- $220 \AA$ ), suggests that HCOO- is not incorporated in the perovskite crystal lattice. ${ }^{[17,20]}$ It is interesting to note that the intensity of the peaks (112), (211), (202), and (224) relative to the intensity of the (110) peak (inset Figure 3a) is significantly larger in the film without MAF. Moreover, the full width at half maximum of the (110) peak is smaller with than without MAF (see the Supporting Information). These two 


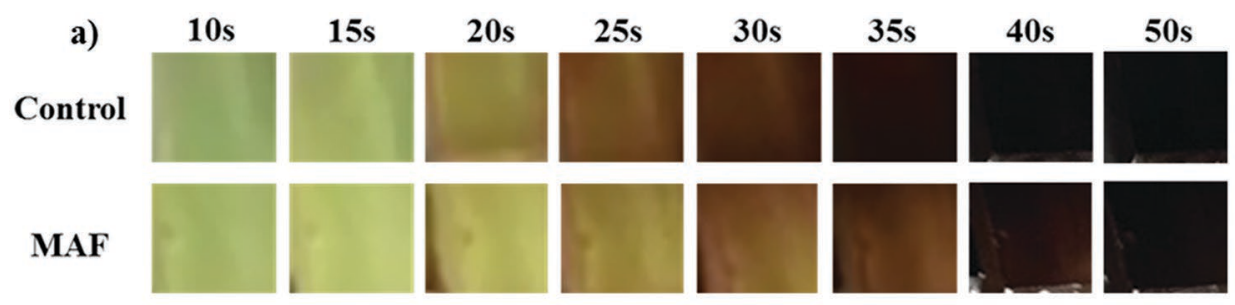

b)
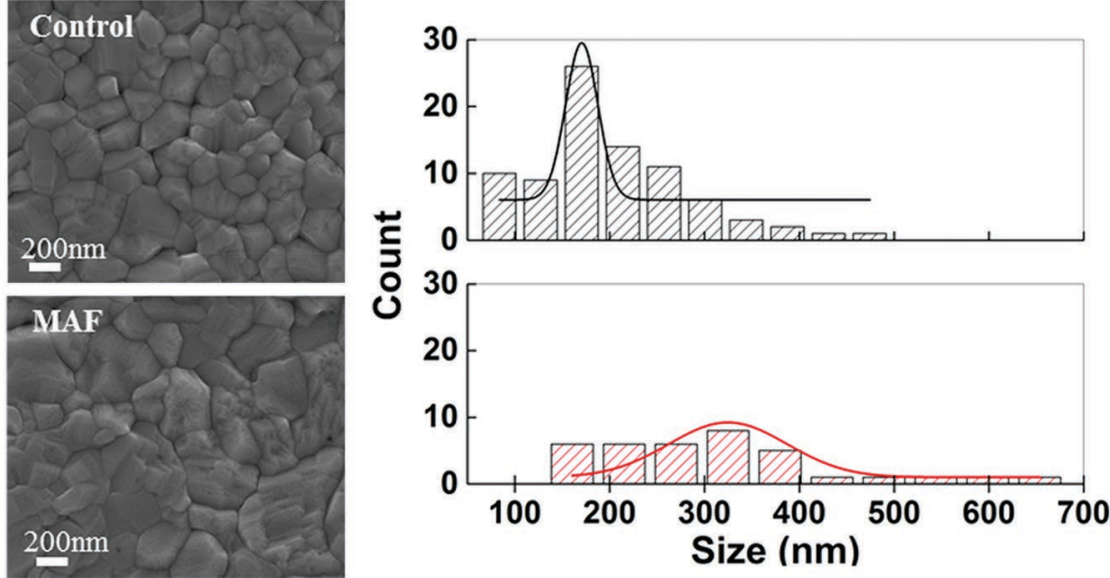

Figure 2. Morphological analysis of the perovskite films with and without MAF. a) Pictures of perovskite films collected at subsequent delay times after posing the substrates on a hotplate at $100^{\circ} \mathrm{C}$. b) (left) Top-view SEM images of perovskite films after $1 \mathrm{~h}$ annealing at $100^{\circ} \mathrm{C}$. (right) Grain sizes distribution as estimated from the SEM images using Nano measurer 1.2 software.

data are compatible with a preferential crystal growth of (110) faces parallel to the substrate (see Figure $2 \mathrm{~b}$ and the Supporting Information), ${ }^{[21]}$ which is also supported by the change in morphology we observed with the SEM imaging.

PSCs with and without MAF in perovskite precursor solution were prepared on compact $\mathrm{SnO}_{2}$, following the procedures

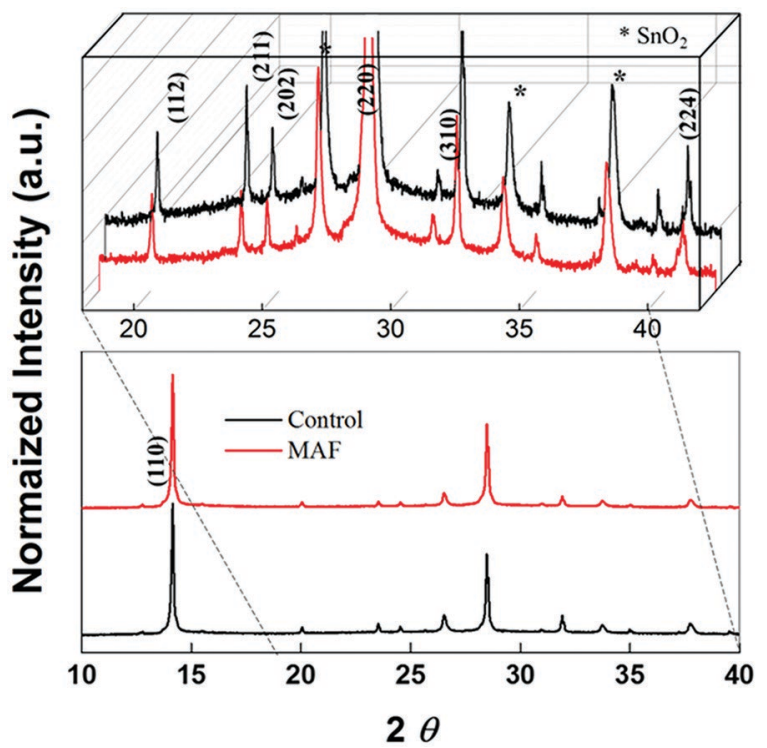

Figure 3. X-ray diffraction diagram of perovskite films deposited on $\mathrm{SnO}_{2}$ substrates with and without MAF, the intensity is normalized to the peak at $14^{\circ}(110)$. Inset: enlarged spectra displaying the relative intensities of the peaks between $18^{\circ}$ and $42^{\circ}$. previously reported by Baena et al. ${ }^{[22]}$ Figure 4a displays the current density-voltage $(J-V)$ curves of the best PSCs with the corresponding metrics reported in Table 1. The data show that MAF improves the short circuit current density $\left(J_{\mathrm{sc}}\right)$ by $1 \mathrm{~mA} \mathrm{~cm}^{-2}$. This is confirmed by the incident photon-to-current efficiency (IPCE) in Figure 4b. We notice that with and without MAF the integrated current density is lower than what is measured from the $J-V$ curves. This trend has been systematically observed also from other groups, and it can in part be attributed to a small spectral mismatch between the solar simulator and the standard AM $1.5 \mathrm{G}$ emission. ${ }^{[19,23]}$ In Figure 4c we reported the statistical analyses (box plot) of the maximum PCE collected from seven independent devices, which confirmed the improvement with MAF. To rule out the impact of the hysteresis on the estimated PCE, we tracked the device maximum power output for $5 \mathrm{~min}$ in order to extract the stabilized maximum PCE. Figure 4d displays that the PCE stabilizes after about $50 \mathrm{~s}$ to $18.9 \%$ for the control and $19.5 \%$ for MAF device (see Table 1), confirming the trend extracted from the $J-V$ curves in Figure 4a. We want to highlight that our best control device matches the highest reported stabilized PCE for planar PSCs $(\approx 19 \%) .{ }^{24,25]}$ Therefore, with MAF we are improving the stateof-the-art, reaching a new record for planar PSC with $19.5 \%$ stabilized PCE.

In order to investigate the origin of the improved performances with the MAF, we performed intensity-modulated photocurrent spectroscopy. ${ }^{[26]}$ In Figure 5, we report the imaginary component frequency spectra of the current response to the light intensity-modulated ( $10 \%$ of the stationary value) around $100 \mathrm{~mW} \mathrm{~cm}{ }^{-2}$ for devices with and without MAF. The spectra show three main features, which have been already 
a)
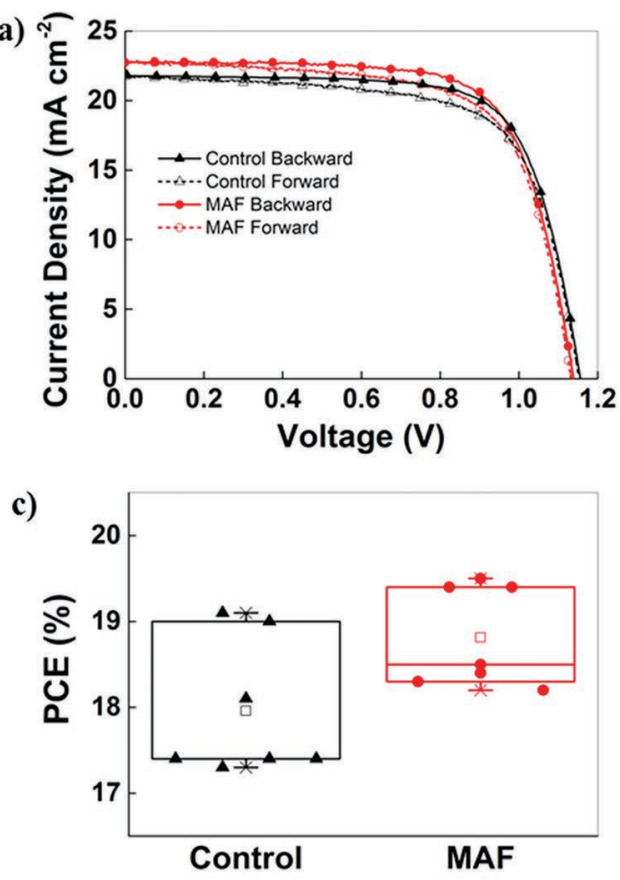

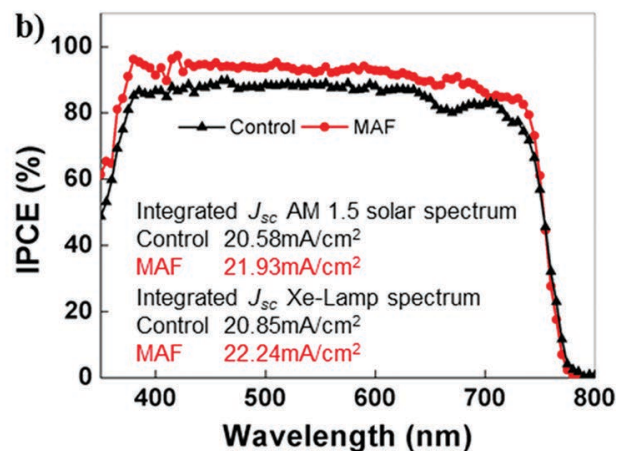

d)

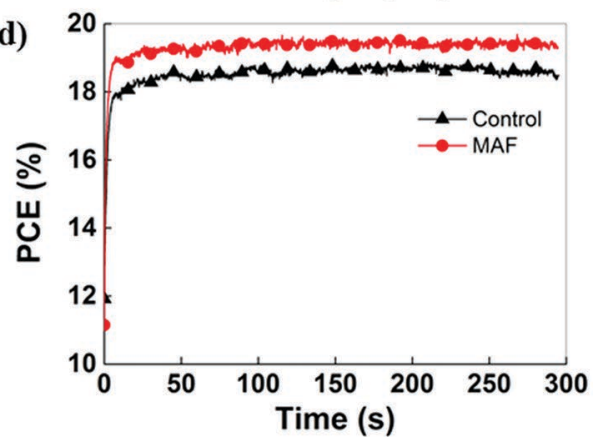

Figure 4. Photovoltaic metrics of perovskite solar cells prepared with and without MAF. a) J-V curves were measured from forward bias to short circuit condition and vice versa at the scan rate of $10 \mathrm{mV} \mathrm{s}^{-1}$ under AM1.5 simulated solar light $\left(94.8 \mathrm{~mW} \mathrm{~cm} \mathrm{~m}^{-2}\right)$. The device active area was defined using a black metal shadow mask with an aperture of $0.16 \mathrm{~cm}^{2}$. b) Incident photon-to-current efficiency (IPCE) curves for the MAF and control device. c) Box plot of the PCE collected from seven devices. d) Maximum power conversion efficiency as function of time from the maximum power point tracking under AM1.5 simulated solar light.

reported by Baena et al. for similar planar PSCs. ${ }^{[27]}$ The peak at low frequency $(0.1 \mathrm{~Hz}-100 \mathrm{~Hz})$ has been correlated to the resonant frequencies of the ions and ion vacancies migration within the perovskite lattice. Here, we note that the peak of the MAF device is shifted toward higher frequency, indicating a faster ion migration. This is in line with what was observed by Baena et al., who reported ions migrating faster in perovskite films composed of larger grains. Moving to higher frequency, there are two more peaks that have been assigned to the resonant frequencies of the charge dynamics within the perovskite and the other device components, such as the hole and the electron transporting layers. While the peak at highest frequency (fast charge dynamics) is rather similar with and without MAF, the peak at intermediated frequency $(1-100 \mathrm{KHz})$ is clearly visible only in the control and almost vanishes in the MAF device.
As we have previously shown, this peak provides information on the slow charge transport dynamics within the device. ${ }^{[28]}$ The fact that its intensity is significantly lower suggests that the slow charge transport pathways are inhibited by the MAF. This behavior correlates with the crystal size distribution we presented in Figure 2b, where we showed that MAF reduces the formation of grains smaller than $150 \mathrm{~nm}$, while they represent a great portion of the size distribution in the film without the MAF. The cross-sectional SEM images (see Supporting Information) of a perovskite film with MAF shows that larger grains can cross the whole thickness of the perovskite film, thus forming a sort of local single crystalline devices. The charge transport through a single crystal is significantly faster than through the grain boundaries of a polycrystalline film. ${ }^{[29,30]}$ Therefore, inhibiting the formation of small crystals eliminates

Table 1. Photovoltaic parameters of best devices with and without MAF: open-circuit voltage $\left(V_{o c}\right)$, short circuit current $\left(U_{s c}\right)$, fill factor (FF), power conversion efficiency as extracted from the $J-V$ curves (PCE, backward and forward scan) and from the stabilized maximum power point (Stab. PCE) after $60 \mathrm{~s}$ of the champion devices in Figure 5 and the average values of each parameter collected by backward scan from seven devices of both control and MAF, respectively.

\begin{tabular}{|c|c|c|c|c|c|c|c|c|c|c|}
\hline & \multicolumn{5}{|c|}{ Champion devices } & \multicolumn{5}{|c|}{ Average of seven devices } \\
\hline & Scan direction & $\begin{array}{c}J_{\mathrm{sc}} \\
{\left[\mathrm{mA} \mathrm{cm}^{-2}\right]}\end{array}$ & $\begin{array}{l}V_{o c} \\
{[V]}\end{array}$ & $\mathrm{FF}$ & $\begin{array}{l}\mathrm{PCE} \\
{[\%]} \\
\end{array}$ & $\begin{array}{c}\text { Stabilized PCE } \\
{[\%]}\end{array}$ & $\begin{array}{c}J_{\mathrm{sc}} \\
{\left[\mathrm{mA} \mathrm{cm}^{-2}\right]}\end{array}$ & $\begin{array}{l}V_{o c} \\
{[V]}\end{array}$ & $\mathrm{FF}$ & $\begin{array}{l}\mathrm{PCE} \\
{[\%]}\end{array}$ \\
\hline \multirow[t]{2}{*}{ Control } & Backward & 21.7 & 1.16 & 0.72 & 19.1 & 18.9 & $21.2 \pm 0.7$ & $1.15 \pm 0.01$ & $0.72 \pm 0.01$ & $18.0 \pm 0.8$ \\
\hline & Forward & 21.7 & 1.15 & 0.69 & 18.1 & & & & & \\
\hline \multirow[t]{2}{*}{ MAF } & Backward & 22.7 & 1.14 & 0.71 & 19.5 & 19.5 & $21.7 \pm 0.8$ & $1.16 \pm 0.02$ & $0.72 \pm 0.02$ & $18.8 \pm 0.6$ \\
\hline & Forward & 22.7 & 1.13 & 0.69 & 18.6 & & & & & \\
\hline
\end{tabular}




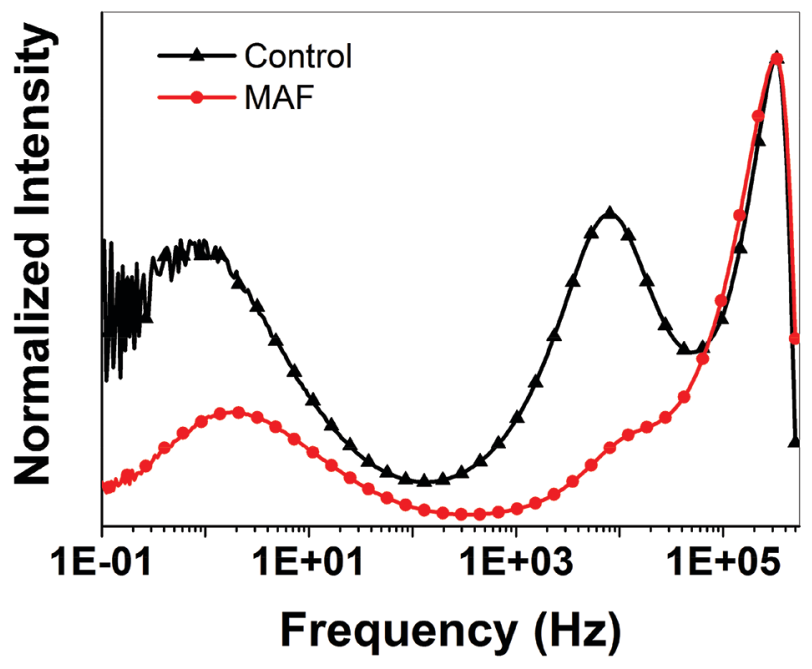

Figure 5. Imaginary component frequency spectra of the current response to the light intensity modulated around $100 \mathrm{~mW} \mathrm{~cm}{ }^{-2}$ for devices with and without MAF. The intensities are normalized to the maximum value.

the slow charge transport pathways, which results in better device performances.

In conclusion, we reported planar perovskite solar cells with a record stabilized power conversion efficiency of $19.5 \%$. We demonstrated that controlling the grain size distribution within the perovskite film is crucial to improve the state-of-the-art device. We made use of a specific ionic liquid, methylammonium formate, to retard the perovskite crystal growth in order to form a compact layer with larger grain sizes. XRD and SEM analyses showed that MAF induces larger crystals in the plane of the substrate. Planar perovskite solar cells prepared with MAF exhibited more effective charge transport, which results in higher power conversion efficiency compared to the state-ofthe-art devices. Using ionic liquids to control the morphology of the perovskite film is a simple, general, and effective method to enhance the efficiency of planar perovskite solar cells. Further advances are expected from using other ionic liquids that can selectively interact with the different elements composing the perovskite crystals.

\section{Experimental Section}

Chemicals and Reagents: All reagents except methylammonium formate and solvents were purchased from commercial sources and used without further purification unless otherwise noted.

Chemical Characterization: ${ }^{1} \mathrm{H}$ NMR spectra were obtained using a Bruker spectrometer $(400 \mathrm{MHz})$ was reported in ppm using DMSO-d as an internal standard. X-ray diffraction (XRD) diagrams were recorded on an X'Pert MPD PRO (Panalytical) equipped with a ceramic tube (Cu anode, $\lambda=1.54060 \AA$ ), a secondary graphite (002) monochromator, and a real time multiple strip (RTMS) $X^{\prime}$ Celerator (Panalytical) in an angle range of $2 \theta=10^{\circ}$ to $40^{\circ}$.

Methylammnonium Formate: MAF was synthesized using a previously reported procedure. ${ }^{[17]} \mathrm{CH}_{3} \mathrm{NH}_{3}(\mathrm{HCOO})$ was synthesized by dropping slowly $6 \mathrm{~mL}$ of formic acid (88 wt\% in water) in methanol to a solution of $20 \mathrm{~mL}$ methylamine (40 wt\% in water) in $10 \mathrm{~mL}$ absolute ethanol cooled at $0{ }^{\circ} \mathrm{C}$. After mixing reagent, the solution was further stirred for $1 \mathrm{~h}$ at $0^{\circ} \mathrm{C}$ under vacuum. Then the solution dried at room temperature under vacuum for $2 \mathrm{~d}$. ${ }^{1} \mathrm{H}$ NMR (400 MHz, DMSO-d): 2.30 (s, 3H), 8.40 $(\mathrm{s}, 1 \mathrm{H}) 8.64(\mathrm{~s}, 3 \mathrm{H})$.

Solar Cells Fabrication: Devices were fabricated on FTO-coated glass substrates. The substrates were cleaned sequentially with Hellmanex in ultrasonic bath for $30 \mathrm{~min}$, then washed with acetone, isopropanol, and finally cleaned with oxygen plasma for $5 \mathrm{~min}$. Electron selective layer preparation $\mathrm{F}: \mathrm{SnO}_{2}$ substrates were cleaned first with acetone, then for 10 min in piranha solution $\left(\mathrm{H}_{2} \mathrm{SO}_{4} / \mathrm{H}_{2} \mathrm{O}_{2} 3: 1 \mathrm{v}: \mathrm{v}\right)$ and then for $10 \mathrm{~min}$ in a plasma cleaner prior to atomic layer deposition (ALD). $\mathrm{SnO}_{2}$ was deposited at $118{ }^{\circ} \mathrm{C}$ using tetrakis(dimethylamino)- tin(IV) (TDMASn, 99.99\%-Sn, Strem Chemicals INC) and ozone at a constant growth rate of $0.065 \mathrm{~nm}$ per cycle measured by ellipsometry. TDMASn was held at $65^{\circ} \mathrm{C}$. Ozone was produced using an ozone generator (AC-2025, IN USA Incorporated) fed with oxygen gas ( $99.9995 \%$ pure, Carbagas) producing a concentration of $13 \%$ ozone in oxygen. Nitrogen was used as a carrier gas (99.9999\% pure, Carbagas) with a flow rate of $10 \mathrm{sccm}$., before perovskite deposition, the pre-made ALD layers were treated with UV ozone for $10 \mathrm{~min}$ to remove byproducts from the deposition process. The perovskite films were deposited from a precursor solution containing $\mathrm{MAI}(1.1 \mathrm{M}$, Dysol) and $\mathrm{PbI}_{2}(1.1 \mathrm{~m}, \mathrm{TCl}$ Chemicals) in anhydrous DMSO (Acros) for $\mathrm{MAPbl}_{3}, \mathrm{FAl}\left(1.1 \mathrm{~m}\right.$, Dyesol), $\mathrm{Pbl}_{2}(1.2 \mathrm{M}, \mathrm{TCl}$ Chemicals $), \mathrm{MABr}(0.2 \mathrm{M}$, Dyesol), and $\mathrm{PbBr}_{2}(0.2 \mathrm{M}, \mathrm{TCl}$ Chemicals) in anhydrous DMF:DMSO $4: 1$ (v/v, Acros) for mixed perovskite. Then home-made MAF was added to perovskite solution as the amount, $5 \mathrm{~mol} \%$ of perovskite. The spin coating program includes two steps, first $1000 \mathrm{rpm}$ for $10 \mathrm{~s}$ with a ramp of $200 \mathrm{rpm} \mathrm{s}^{-1}$, then $6000 \mathrm{rpm}$ for $30 \mathrm{~s}$ with a ramp of $2000 \mathrm{rpm} \mathrm{s}^{-1}$. $15 \mathrm{~s}$ before the end of the spin-coating program, chlorobenzene was gently dropped on the spinning substrate. The substrate was then heated at $100{ }^{\circ} \mathrm{C}$ for $1 \mathrm{~h}$ on a hotplate in the nitrogen-filled glovebox. The hole transporting material (HTM) was subsequently deposited on the top of the perovskite layer by spin coating from solution at $4000 \mathrm{rpm}$ for $20 \mathrm{~s}$ with a ramp of $2000 \mathrm{rpm} \mathrm{s}^{-1}$. The HTM solution was prepared by dissolving the compounds (spiro-OMeTAD) in chlorobenzene at concentration of $70 \times 10^{-3} \mathrm{M}$, with the addition of $50 \mathrm{~mol} \%$ of bis (trifluoromethanesulfonyl) imide (Aldrich) from a stock solution of $1.8 \mathrm{~m}$ in acetonitrile, $330 \mathrm{~mol} \%$ of tert-butylpyridine (Aldrich), and $3 \mathrm{~mol} \%$ of Tris (2-(1H-pyrazol-1-yl)-4-tertbutylpyridine)- cobalt(III) Tris(bis (trifluoromethylsulfonyl)imide) (Dyesol) from a stock solution $0.25 \mathrm{~m}$ in acetonitrile. Finally, $80 \mathrm{~nm}$ gold layer was deposited by thermal evaporation under high vacuum, using a shadow masking to pattern the electrodes.

Perouskite Film Characterization: A ZEISS Merlin HR-SEM was used to characterize the morphology of the device top view and crosssection. X-ray diffraction (XRD) diagrams were recorded on an X'Pert MPD PRO (Panalytical) equipped with a ceramic tube ( $\mathrm{Cu}$ anode, $\lambda=$ $1.54060 \AA$ ) , a secondary graphite (002) monochromator, and an RTMS $X^{\prime}$ Celerator (Panalytical) in an angle range of $2 \theta=10^{\circ}$ to $40^{\circ}$. Absorption spectral measurements were recorded using Varian Cary5 UV-visible spectrophotometer. Photoluminescence spectra were obtained with Florolog 322 (Horiba Jobin Ybon Ltd.) with the range of wavelength from 620 to $850 \mathrm{~nm}$ by exciting at $460 \mathrm{~nm}$. The samples were mounted at $60^{\circ}$ and the emission recorded at $90^{\circ}$ from the incident beam path. Time-correlated single-photon counting (TCSPC) measurement of perovskite films for fluorescence lifetime data was collected over an area of $26.36 \times 26.36 \mathrm{~mm}^{2}$ using a confocal laser scanning microscope Leica TCS SP8 $(63 \times / 1.40)$. A $440 \mathrm{~nm}$ diode laser (1.25 MHz repetition rate) was used for excitation, and a hybrid detector for single molecule detection was used for collection of photons emitted between 700 and $800 \mathrm{~nm}$. A TCSPC module (PicoHarp 300 from PicoQuant) was used to analyze the number of photons as a function of time, as they arrived at the detector. For NMR analysis, the mixed perovskite films with/without MAF sintered at $100^{\circ} \mathrm{C}$ were rinsed with butanol for $1 \mathrm{~min}$ in the gloves box after cooling down at $25{ }^{\circ} \mathrm{C}$ to remove residual MAF and then dried on hotplate $100{ }^{\circ} \mathrm{C}$ to evaporate solvent. Dried film was scratched to powder, which was dissolving in $\mathrm{D}_{2} \mathrm{O}$.

Solar Cell Characterization: Current-voltage characteristics were recorded by applying an external potential bias to the cell while recording the generated photocurrent with a digital source meter (Keithley Model 2400). The light source was a $450 \mathrm{~W}$ xenon lamp 
(Oriel) equipped with a SchottK113 Tempax sunlight filter (Praezisions Glas \& Optik $\mathrm{GmbH}$ ) to match the emission spectrum of the lamp to the AM1.5G standard. Before each measurement, the exact light intensity was determined using a calibrated Si reference diode equipped with an infrared cut-off filter (KG-3, Schott). The scan rate was $10 \mathrm{mV} \mathrm{s}^{-1}$. Maximum power point tracking was performed with Keithley model 2400 driven by a homemade algorithm developed in Igorpro software. The cell was initially biased at $1 \mathrm{~V}$. The bias voltage was decreased of $5 \mathrm{mV}$ each $500 \mathrm{~ms}$ toward the maximum power point. For each voltage step the algorithm evaluated if the derivative of the power over the time was positive or negative. If the derivative was positive the scan direction remained the same. On the contrary the algorithm changed direction if the derivative was negative. When the bias voltage reached the maximum power point the applied bias oscillated within 10-15 $\mathrm{mV}$ perturbing and observing continuously the solar cell under illumination. IPCE spectra were recorded as functions of wavelength under a constant white light bias of $\approx 10 \mathrm{~mW} \mathrm{~cm}{ }^{-2}$ supplied by an array of white light emitting diodes. The excitation beam coming from a $300 \mathrm{~W}$ xenon lamp (ILC Technology) was focused through a Gemini-180 double monochromator (Jobin Yvon Ltd.) and chopped at $\approx 2 \mathrm{~Hz}$. The signal was recorded using a Model SR830 DSP Lock-In Amplifier (Stanford Research Systems). All measurements were conducted using a nonreflective metal aperture of $0.16 \mathrm{~cm}^{2}$ to define the active area of the device and avoid light scattering through the sides. Intensity-modulated photocurrent spectroscopy was performed using Autolab PGSTAT302N according to procedures previously reported. ${ }^{[26]}$

\section{Supporting Information}

Supporting Information is available from the Wiley Online Library or from the author.

\section{Acknowledgements}

M.G. thanks the financial support from the Swiss National Science Foundation, the SNSF-NanoTera (SYNERGY) and Swiss Federal Office of Energy (SYNERGY), CCEM-CH in the 9th call proposal 906: CONNECT PV, the SNSF NRP70 "Energy Turnaround", the King Abdulaziz City for Science and Technology (KACST), and the European Union's Horizon 2020 research and innovation programme under the grant agreement no. 687008 is gratefully acknowledged. The information and views set out in this article are those of the author(s) and do not necessarily reflect the official opinion of the European Union. Neither the European Union institutions and bodies nor any person acting on their behalf may be held responsible for the use which may be made of the information contained herein. A.A. has received funding from the European Union's Seventh Framework Programme for research, technological development, and demonstration under grant agreement no. 291771.

Received: April 11, 2016 Revised: June 13, 2016 Published online:

[1] A. Kojima, K. Teshima, Y. Shirai, T. Miyasaka, J. Am. Chem. Soc. 2009, 137, 6050

[2] M. M. Lee, J. Teuscher, T. Miyasaka, T. N. Murakami, H. J. Snaith, Science 2012, 338, 643.

[3] N. J. Jeon, J. H. Noh, W. S. Yang, Y. C. Kim, S. Ryu, J. Seo, S. I. Seok, Nature 2015, 517, 476.

[4] National Renewable Energy Laboratory(NREL), http://www.nrel. gov/ncpv/images/efficiency_chart.jpg (accessed: April 2016).
[5] B. P. Fingerhut, W. Zinth, R. de Vivie-Riedle, Phys. Chem. Chem. Phys. 2010, 12, 422.

[6] Z. L. Ku, Y. G. Rong, M. Xu, T. F. Liu, H. W. Han, Sci. Rep.-UK. 2013 , 3, 3132 .

[7] S. Albrecht, M. Saliba, J. P. C. Baena, F. Lang, L. Kegelmann, M. Mews, L. Steier, A. Abate, J. Rappich, L. Korte, R. Schlatmann, M. K. Nazeeruddin, A. Hagfeldt, M. Gratzel, B. Rech, Energy Environ. Sci. 2016, 9, 81.

[8] H. J. Snaith, A. Abate, J. M. Ball, G. E. Eperon, T. Leijtens, N. K. Noel, S. D. Stranks, J. T. W. Wang, K. Wojciechowski, W. Zhang, J. Phys. Chem. Lett. 2014, 5, 1511.

[9] C. S. Ponseca, T. J. Savenije, M. Abdellah, K. B. Zheng, A. Yartsev, T. Pascher, T. Harlang, P. Chabera, T. Pullerits, A. Stepanov, J. P. Wolf, V. Sundstrom, J. Am. Chem. Soc. 2014, 136, 5189.

[10] W. S. Yang, J. H. Noh, N. J. Jeon, Y. C. Kim, S. Ryu, J. Seo, S. I. Seok, Science 2015, 348, 1234

[11] Q. Chen, H. P. Zhou, Z. R. Hong, S. Luo, H. S. Duan, H. H. Wang, Y. S. Liu, G. Li, Y. Yang, J. Am. Chem. Soc. 2014, 136, 622.

[12] F. Z. Huang, Y. Dkhissi, W. C. Huang, M. D. Xiao, I. Benesperi, S. Rubanov, Y. Zhu, X. F. Lin, L. C. Jiang, Y. C. Zhou, A. Gray-Weale, J. Etheridge, C. R. McNeill, R. A. Caruso, U. Bach, L. Spiccia, Y. B. Cheng, Nano Energy 2014, 10, 10.

[13] D. Bi, W. Tress, M. I. Dar, P. Gao, J. Luo, C. Renevier, K. Schenk, A. Abate, F. Giordano, J. P. Correa Baena, J. D. Decoppet, S. M. Zakeeruddin, M. K. Nazeeruddin, M. Gratzel, A. Hagfeldt, Sci. Adv. 2016, 2, e1501170.

[14] P. W. Liang, C. Y. Liao, C. C. Chueh, F. Zuo, S. T. Williams, X. K. Xin, J. Lin, A. K. Jen, Adv. Mater. 2014, 26, 3748.

[15] D. T. Moore, K. W. Tan, H. Sai, K. P. Barteau, U. Wiesner, L. A. Estroff, Chem. Mater. 2015, 27, 3197.

[16] M. Shahiduzzaman, K. Yamamoto, Y. Furumoto, T. Kuwabara, K. Takahashi, T. Taima, RSC Adv. 2015, 5, 77495.

[17] J. P. Belieres, C. A. Angell, J. Phys. Chem. B 2007, 111, 4926.

[18] J. Catalano, A. Murphy, Y. Yao, G. P. A. Yap, N. Zumbulyadis, S. A. Centeno, C. Dybowski, Dalton T. 2015, 44, 2340.

[19] N. J. Jeon, J. H. Noh, Y. C. Kim, W. S. Yang, S. Ryu, S. II Seol, Nat. Mater. 2014, 13, 897.

[20] F. Holtzberg, B. Post, I. Fankuchen, J. Chem. Phys. 1952, 20, 198.

[21] I. M. Hermes, S. A. Bretschneider, V. W. Bergmann, D. Li, A. Klasen, J. Mars, W. Tremel, F. Laquai, H. J. Butt, M. Mezger, R. Berger, B. J. Rodriguez, S. A. L. Weber, J. Phys. Chem. C 2016, 120, 5724.

[22] J. P. C. Baena, L. Steier, W. Tress, M. Saliba, S. Neutzner, T. Matsui, F. Giordano, T. J. Jacobsson, A. R. S. Kandada, S. M. Zakeeruddin, A. Petrozza, A. Abate, M. K. Nazeeruddin, M. Gratzel, A. Hagfeldt, Energy Environ. Sci. 2015, 8, 2928.

[23] J. W. Lee, T. Y. Lee, P. J. Yoo, M. Gratzel, S. Mhaisalkar, N. G. Park, J. Mater. Chem. A 2014, 2, 9251.

[24] J. H. Heo, M. H. Lee, H. J. Han, B. R. Patil, J. S. Yu, S. H. Im, J. Mater. Chem. A 2016, 4, 1572.

[25] Y. Shao, Y. Yuan, J. Huang, Nat. Energy 2016, 1, 15001.

[26] K. Zhu, N. Kopidakis, N. R. Neale, J. van de Lagemaat, A. J. Frank, J. Phys. Chem. B 2006, 110, 25174.

[27] J. P. C. Baena, M. Anaya, G. Lozano, Adv. Mater. 2016, 28, 5031.

[28] F. Giordano, A. Abate, J. P. Correa Baena, M. Saliba, T. Matsui, S. H. Im, S. M. Zakeeruddin, M. K. Nazeeruddin, A. Hagfeldt, M. Graetzel, Nat. Commun. 2016, 7, 10379.

[29] W. Zhang, M. Saliba, D. T. Moore, S. K. Pathak, M. T. Horantner, T. Stergiopoulos, S. D. Stranks, G. E. Eperon, J. A. Alexander-Webber, A. Abate, A. Sadhanala, S. Yao, Y. Chen, R. H. Friend, L. A. Estroff, U. Wiesner, H. J. Snaith, Nat. Commun. 2015, 6, 6142.

[30] J. H. Im, I. H. Jang, N. Pellet, M. Gratzel, N. G. Park, Nat. Nanotechnol. 2014, 9, 927 